\title{
Escarificação e ácido giberélico na emergência e crescimento de plântulas de biribá
}

\author{
Scarification and gibberellic acid on emergence and seedling growth of Biriba
}

\author{
Luiz Fernandes Cardoso Campos ${ }^{\mathrm{I}^{*}}$ Camila Meira de Abreu ${ }^{\mathrm{II}}$ \\ Ricardo Neves Guimarães ${ }^{I}$ Alexsander Seleguini ${ }^{I I I}$
}

\section{RESUMO}

\begin{abstract}
Nas sementes de anonáceas, há substâncias inibidoras de germinação que provocam dormência e que, juntamente com um tegumento resistente e impermeável, proporcionam fatores antagônicos à germinação rápida e uniforme. Objetivou-se neste trabalho estudar o efeito da escarificação mecânica e embebição de sementes em ácido giberélico sobre emergência e crescimento inicial de plântulas de biribá. O experimento foi conduzido no Setor de Horticultura da Escola de Agronomia, Universidade Federal de Goiás (EA/UFG), Goiânia, GO. Os tratamentos consistiram da combinação dos fatores escarificação (sementes escarificadas mecanicamente ou não) e embebição de sementes por 20 horas, em concentrações crescentes de ácido giberélico (0, $125,250,500$ e $\left.1000 \mathrm{mg} \mathrm{L}^{-1}\right)$, em delineamento experimental de blocos ao acaso. As caraterísticas avaliadas foram a porcentagem $e$ indice de velocidade de emergência de plântulas aos 24, 34 e 43 dias após a semeadura, o comprimento da raiz principal e da parte aérea, a massa seca das raizes, da parte aérea e total de plântulas. A escarificação mecânica em sementes de biribá promove maior porcentagem e indice de velocidade de emergência de plântulas. O aumento das concentrações de ácido giberélico incrementa linearmente a percentagem e o indice de velocidade de emergência, além do comprimento da raiz principal e da parte aérea de plântulas. Por permitir emergência mais rápida e consequente ganho de tempo na produção de mudas, recomendase que sementes de biribá sejam escarificadas.
\end{abstract}

Palavras-chave: Rollinia mucosa (Jacq.) Baill, regulador de crescimento, superação de dormência.

\section{ABSTRACT}

In Annonaceae seed germination there inhibitory substances that cause dormancy, which together with a tough seed coat and antagonistic factors provide the rapid and uniform germination. The objective of this research was to study the effect of mechanical scarification and seed soaking in gibberellic acid on emergence and early growth of Biriba plantlets. The experiment was conducted in the Horticulture Sector of the School of Agronomy, Universidade Federal de Goiás (EA/UFG), Goiânia, GO. The seeds used in the test were manually extracted from fruits harvested in the municipality of Itapuranga, GO. Treatments included a combination of factors scarification (seeds scarified mechanically or not) and seed soaking for 20 hours with increasing concentrations of gibberellic acid $(0,125,250,500$ and 1000mg $\mathrm{L}^{-1}$ ) in experimental design of randomized blocks. The characteristics evaluated were the percentage and emergency speed index of plantlets at 24, 34 and 43 days after sowing, the length of the main root and aerial part, dry weight of root, shoot and total of plantlets. The mechanical scarification in Biribá seeds promotes higher percentage and of plantlets emergence speed index. Increased concentrations of gibberellic acid linearly increase the percentage and the emergency speed index and the length of the main root and shoots of plantlets. Allowing more rapid emergence and consequently saving time in the production of seedlings, it is recommended scarification of biribá seeds.

Key words: Rollinia mucosa (Jacq.) Baill, growth regulators, dormancy breaking.

\section{INTRODUÇÃO}

A família Anonaceae é composta por cerca de 40 gêneros e mais de 2000 espécies, das quais as comestíveis são distribuídas em cinco gêneros: Anona, Rollinia, Duguetia, Uvaria e Asimira, sendo que os dois primeiros têm importância econômica (NOGUEIRA et al., 2005). Segundo WATANABE et al. (2014), o volume de anonáceas comercializado na Companhia

\footnotetext{
'Programa de Pós-graduação em Agronomia (PPGA), Universidade Federal de Goiás (UFG), 74690-900, Goiânia, GO, Brasil. E-mail: luizfernandescampos@hotmail.com. *Autor para correspondência.

IIPrograma de Pós-graduação em Engenharia Agrícola (PPEA), Universidade Estadual de Goiás (UEG), Anápolis, GO, Brasil.

IIISetor de Horticultura, UFG, Goiânia, GO, Brasil. 
de Entrepostos e Armazéns Gerais do Estado de São Paulo (CEAGESP) alcançou, em 2012, 6.420 toneladas, volume que representava, naquele ano, $61 \%$ do comércio dessas frutas no Brasil. Dentre as espécies comercializadas, destacou-se a atemoia e a pinha, que responderam por 54 e $41 \%$ do volume comercializado.

Embora pouco conhecida frente às anonáceas tradicionalmente cultivadas no Brasil, o biribá (Rollinia mucosa (Jacq.) Baill), nativo das matas pluviais atlântica e amazônica brasileiras (SANTOS et al., 2005), tem potencial para ser incorporado no sistema produtivo de frutas do Brasil. O sabor e a qualidade dos frutos, aliados à rusticidade das plantas, têm despertado o interesse de produtores por esta cultura em diferentes regiões do Brasil (FERREIRA et al., 2009). Ademais, o interesse por essa espécie cresceu nos últimos anos para utilização como porta-enxerto em outras anonáceas de maior valor comercial, como a pinha ou fruta do conde (Annona squamosa L.), a graviola (Annona muricata L.) e a atemoia, híbrido interespecífico entre a cherimoia (Annona cherimola) e a fruta-do-conde.

As anonáceas, principalmente as espécies cultivadas, são atacadas por brocas do colo, brocas do tronco e fungos de solo, o que inviabiliza ou dificulta a formação de mudas e o estabelecimento dos pomares. A utilização de porta-enxerto resistente, como o biribá, é indispensável para garantir o sucesso comercial (FERREIRA et al., 2009; ALMEIDA et al., 2010). Contudo, as sementes dessas plantas têm substâncias inibidoras de germinação que provocam dormência, que, juntamente com um tegumento resistente e impermeável, podem proporcionar fatores antagônicos à germinação rápida e uniforme. Segundo FERREIRA et al. (2009), a superação da dormência pode ser realizada utilizando-se escarificação mecânica, térmica ou química.

Para os viveiristas e produtores, o mecanismo de dormência é uma desvantagem por induzir grande desuniformidade entre as mudas e maior demanda de tempo na sua produção (EIRA et al., 1993). Assim, o estudo de metodologias que melhorem a germinação das sementes e o desempenho das mudas no viveiro se torna importante, contribuindo para acelerar e uniformizar o estabelecimento inicial das plantas no campo (ROVERSI et al., 2002).

Alguns métodos, como a escarificação e utilização do ácido giberélico $\left(\mathrm{GA}_{3}\right)$ na superação de dormência das sementes de anonáceas, são alternativas que visam altos índices de germinação e melhor desenvolvimento de plântulas. Em estudo da superação de dormência em sementes de atemoia (A. squamosa L. X $A$. cherimola L.) e pinha ( $A$. squamosa L.), por meio da escarificação de sementes, com lixa, e utilização de ácido giberélico, STENZEL et al. (2003) verificaram que 50 ou $100 \mathrm{ppm}$ de $\mathrm{GA}_{3}$ proporcionam porcentagem e velocidade de germinação significativamente superiores aos demais tratamentos (imersão em água a 5 e $30^{\circ} \mathrm{C}$ ).

A ação das giberelinas (GAs) ou dos ácidos giberélicos no processo germinativo é bem conhecido. Segundo TAIZ \& ZEIGER (2004), elas atuam no controle da hidrólise do tecido de reserva para o fornecimento de energia ao embrião, promovendo o alongamento celular, induzindo o desenvolvimento da radícula através do endosperma ou tegumento. Possuem ainda efeito de estimulação no processo germinativo quando aplicadas em sementes com dormência e também naquelas não dormentes. Em trabalho com imersão de sementes de pinha em ácido giberélico, em água quente e a escarificação com lixa, MENEGAZZO et al. (2012) verificaram que utilização de ácido giberélico foi o melhor método para superação da dormência, no entanto experimentos que definam a melhor concentração desse fitorregulador ainda são necessários.

Conhecer o mecanismo de dormência e a melhor forma de sua superação é de grande relevância para produção de mudas de qualidade (LULA et al., 2000). Assim, objetivou-se com este trabalho estudar o efeito da escarificação mecânica e embebição em ácido giberélico de sementes de biribá, sobre emergência e crescimento inicial das plântulas.

\section{MATERIAL E MÉTODOS}

O experimento foi conduzido no Setor de Horticultura da Escola de Agronomia, Universidade Federal de Goiás (EA/UFG), Goiânia, GO, com sementes obtidas de frutos de biribá colhidos em uma propriedade rural, localizada no município de Itapuranga-GO, a $15^{\circ} 34^{\prime}$ '29' de Latitude Sul, 50 $00^{\prime}$ $26^{\prime}$ "de Longitude Oeste e altitude média de $635 \mathrm{~m}$. O clima da região é do tipo Aw de Köppen (tropical chuvoso), caracterizado pela presença de invernos secos e verões chuvosos.

As sementes foram extraídas de cerca de 30 frutos de uma única planta matriz, procurandose assim reduzir a variabilidade na germinação pelo maior controle da dormência do tipo primária, que é programada geneticamente. Os frutos totalmente maduros foram despolpados manualmente, utilizando peneira e água corrente e, após a extração, as sementes foram secas sobre papel em local sombreado por três dias. O grau de umidade das sementes após a secagem situou-se em torno de $9,65 \%$ e foi determinado de acordo 
com as Regras de Análise de Sementes, pelo método da estufa a $105^{\circ} \mathrm{C}$ por 24 horas (BRASIL, 2009).

A semeadura foi realizada em bandejas plásticas perfuradas, utilizando como substrato areia média, esterilizada em autoclave por 1 hora, a $121^{\circ} \mathrm{C}$ e $1 \mathrm{~atm}$ de pressão, as quais foram mantidas em prateleiras dotadas de iluminação artificial ( 8 horas de luz por dia) em uma sala de crescimento, mantida em $25 \pm 2^{\circ} \mathrm{C}$.

O delineamento experimental utilizado foi o de blocos ao acaso, em esquema fatorial $2 \times 5$, (escarificação de sementes $\mathrm{x}$ doses de ácido giberélico), em quatro repetições, sendo 25 sementes em cada parcela.

Os níveis estudados do fator escarificação foram: sementes escarificadas e não escarificadas. A escarificação foi realizada com corte do tegumento da semente, com auxílio de tesoura de poda, no lado oposto ao hilo (MENEGAZZO et al., 2012). No tratamento com regulador de crescimento, as sementes foram mantidas embebidas por 20 horas, em soluções de ácido giberélico, nas concentrações de $0,125,250,500$ e $1000 \mathrm{mg} \mathrm{L}^{-1}$.

Com início da emergência, foram realizadas contagens diárias, sendo considerada emergida a plântula cujo caulículo estava acima do nível do substrato. Foram analisadas as seguintes variáveis: porcentagem de emergência aos 24, 34 e 43 dias após a semeadura (DAS); índice velocidade de emergência (IVE), calculado aos 24, 34 e 43 DAS, por meio da fórmula proposta por MAGUIRE (1962), em que: $\mathrm{IVE}=\mathrm{E} 1 / \mathrm{N} 1+\mathrm{E} 2 / \mathrm{N} 2+\ldots \mathrm{En} / \mathrm{Nn}$, onde: $\mathrm{E} 1$, E2, ... En refere-se ao número de plântulas emergidas computadas na primeira, segunda e última contagem; $\mathrm{N} 1, \mathrm{~N} 2, \ldots \mathrm{Nn}$ refere-se ao número de dias desde a semeadura até a primeira, segunda e última contagem.

Quando se atingiu a estabilização do processo de germinação, foram coletadas cinco plântulas por parcela para avaliação do comprimento da raiz principal $(\mathrm{cm})$ e da parte aérea $(\mathrm{cm})$, massa seca das raízes $(\mathrm{g})$ e da parte aérea $(\mathrm{g})$ e massa seca total de plântula $(\mathrm{g})$. O comprimento da parte aérea e da raiz principal foram mensurados com o auxílio de uma régua graduada, considerando o comprimento do colo ao ápice da parte aérea e do colo ao ápice da raiz principal, respectivamente. Em seguida, o material foi colocado para secar em estufa com circulação forçada de ar a $70^{\circ} \mathrm{C}$ até massa constante, sendo, em seguida, realizadas as determinações da massa seca das raízes e da parte aérea, em balança analítica.

Os dados foram submetidos à análise de variância, as médias dos níveis do fator qualitativo (escarificação), comparadas pelo teste de Tukey a $5 \%$ e as médias do fator quantitativo (doses de $\mathrm{GA}_{3}$ ) submetidas a ajustes de regressão polinomial, utilizando-se o pacote estatístico Assistat 7.7 (SILVA \& AZEVEDO, 2009).

\section{RESULTADOS E DISCUSSÃO}

A emergência das plântulas iniciou-se aos 20 dias após a semeadura (DAS) e estabilizou-se aos 43 DAS, com porcentagem de emergência alcançando $87 \%$, independentemente dos tratamentos. Esses resultados caracterizam um processo de emergência desuniforme e com distribuição temporal, que confere uma vantagem adaptativa à espécie, entretanto, esse comportamento pode constituir um problema para a produção de mudas de qualidade e consequentemente na domesticação da espécie. FERREIRA \& RIBEIRO (2006) relataram 60 a $80 \%$ de germinação em sementes de biribá entre 20 e 30 dias após a semeadura.

Nas sementes submetidas à escarificação, constatou-se maior porcentagem de emergência, tanto na avaliação aos 24, como aos 34 DAS, refletindo também em um maior IVE (Tabela 1). Sugere-se que a escarificação, por favorecer a embebição das sementes e, consequentemente, a superação de dormência tegumentar, tenha facilitado o processo germinativo, culminando como maiores índices de emergência e velocidade de emergência. Resultados semelhantes foram encontrados por LORENZI (2002), PEREIRA et al. (2004) e FERREIRA et al. (2009). Quanto maior valor de IVE, menor a exposição das sementes às condições adversas do meio, como ataque de fungos e insetos, além de menor permanência das mudas no viveiro (DUTRA et al., 2012), resultando em maior eficiência no processo produtivo de mudas.

Quando se combinou a escarificação mecânica das sementes com a utilização do $\mathrm{GA}_{3}$, verificou-se uma potencialização da emergência de plântulas, refletindo em aumentos lineares na porcentagem e no índice de velocidade de emergência, avaliados aos 24 DAS (Figuras 1 e 2). A escarificação prévia realizada no lado oposto ao hilo pode ter contribuído para o aumento da permeabilidade do tegumento à absorção da solução de ácido giberélico. Mesmo comportamento foi verificado por ALVES et al. (2000) e PEREIRA et al. (2004), respectivamente, em sementes de duas espécies de Bauhinia e em araticum, que foram escarificadas mecanicamente e posteriormente embebidas em ácido giberélico. $\mathrm{O}$ efeito positivo do GA3 na promoção da germinação de araticum (A. crassiflora Mart), encontrado neste trabalho corroboram com estudos conduzidos por 
Tabela 1 - Porcentagem e índice de velocidade de emergência (IVE) de plântulas aos 34 e 43 dias após a semeadura (DAS), comprimento da raiz principal e da parte aérea, massa seca das raízes, da parte aérea e total de plântulas de biribazeiro em função da escarificação mecânica ou não das sementes. Goiânia, GO, 2013.

\begin{tabular}{lccc}
\hline Variáveis & Escarificada & Não-escarificada & CV (\%) \\
\hline Emergência de plântulas 24 DAS (\%) & $14 \mathrm{a}$ & $5 \mathrm{~b}$ & 17,50 \\
Emergência de plântulas 34 DAS (\%) & $76 \mathrm{a}$ & $65 \mathrm{~b}$ & 18,52 \\
Emergência de plântulas 43 DAS (\%) & $88 \mathrm{a}$ & $86 \mathrm{a}$ & 12,70 \\
IVE 24 DAS & $0,15 \mathrm{a}$ & $0,05 \mathrm{~b}$ & 8,70 \\
IVE 34 DAS & $0,68 \mathrm{a}$ & $0,54 \mathrm{~b}$ & 24,53 \\
IVE 43 DAS & $0,75 \mathrm{a}$ & $0,68 \mathrm{~b}$ & 14,75 \\
Comprimento da raiz principal $(\mathrm{cm})$ & $6,92 \mathrm{a}$ & $7,03 \mathrm{a}$ & 22,12 \\
Comprimento da parte aérea $(\mathrm{cm})$ & $7,97 \mathrm{a}$ & $6,71 \mathrm{~b}$ & 18,37 \\
Massa seca das raízes $(\mathrm{g})$ & $0,036 \mathrm{~b}$ & $0,044 \mathrm{a}$ & 17,82 \\
Massa seca da parte aérea $(\mathrm{g})$ & $0,042 \mathrm{a}$ & $0,045 \mathrm{a}$ & 13,16 \\
Massa seca total $(\mathrm{g})$ & $0,078 \mathrm{~b}$ & $0,089 \mathrm{a}$ & 13,01 \\
\hline
\end{tabular}

Médias seguidas da mesma letra, na linha, não diferem entre si pelo teste de Tukey a 5\% de probabilidade.

outros autores como HERNÁNDEZ (1993) com cherimoia (A. cherimola L.); STENZEL et al. (2003) com atemóia e pinha, FERREIRA et al. (2002) com fruta do conde e SOUSA et al. (2008) com pinha. Quanto à escarificação, LORENZI (2002), observou que escarificação mecânica e química em araticum (A. crassiflora Mart.) aumenta a taxa de germinação, podendo atingir índices superiores a 50\%.

Independentemente da escarificação mecânica das sementes, observou-se que a aplicação de $\mathrm{GA}_{3}$ incrementou linearmente o IVE, avaliado aos 34 DAS (Figura 2B). Segundo METIVIER (1979), o ácido giberélico atua na produção da enzima $\alpha$ amilase, que atua na degradação do amido, promovendo uma germinação mais rápida. Resultados semelhantes foram obtidos por LIMA-BRITO et al. (2006) em sementes de pinha tratadas com ácido giberélico.

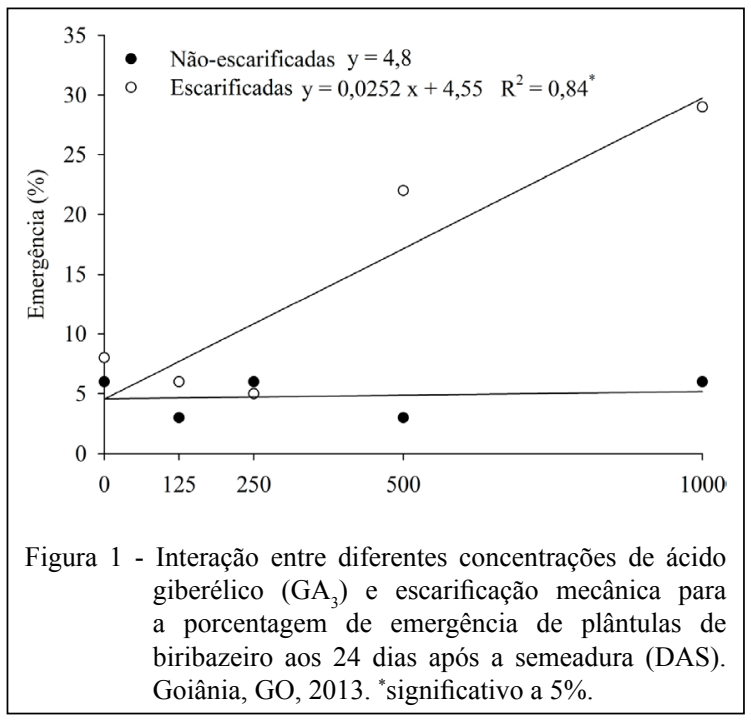

Para os componentes biométricos das plântulas (Tabela 1), observaram-se diferenças significativas entre os níveis do fator escarificação para comprimento da parte aérea, massa seca de raízes e massa seca total, cujo maior comprimento da parte aérea foi verificado em plântulas oriundas de sementes escarificadas, provavelmente devido ao aumento do IVE verificado nesses lotes de sementes. A rápida germinação e estabelecimento de plantas favorecem o desenvolvimento de estruturas vegetativas, pois, segundo VIEIRA \& CARVALHO (1994), sementes de alto vigor conseguem mobilizar com maior rapidez suas reservas energéticas, proporcionando maior crescimento inicial e desenvolvimento.

Para a altura de plântula de biribá, a escarificação mecânica das sementes, como tratamento pré-germinativo, foi significativo, enquanto, para a massa seca de raízes e massa seca total de plântula de biribá, o maior valor de média foi verificado para as sementes não-escarificadas. Esses resultados diferem dos de FERREIRA et al. (2009) avaliando plântulas de biribá e dos de AVELINO et al. (2012), que verificaram, para a massa seca das plântulas de jucá (Caesalpinia ferrea Mart. ex Tul. var. ferrea), que a escarificação mecânica e escarificação química mais 24 horas de embebição, destacaram-se como os melhores tratamentos.

A elevação das concentrações de $\mathrm{GA}_{3}$ proporcionou aumentos lineares no crescimento das plântulas de biribá, no tocante ao comprimento da parte aérea e da raiz principal (Figura 2C e D), corroborando o observado por MENEGAZZO et al. (2012). Esses resultados provavelmente se deram pelo efeito direto do $\mathrm{GA}_{3}$, promovendo a germinação da semente e estimulando o crescimento do embrião por induzir a produção de hidrolases para a quebra e 


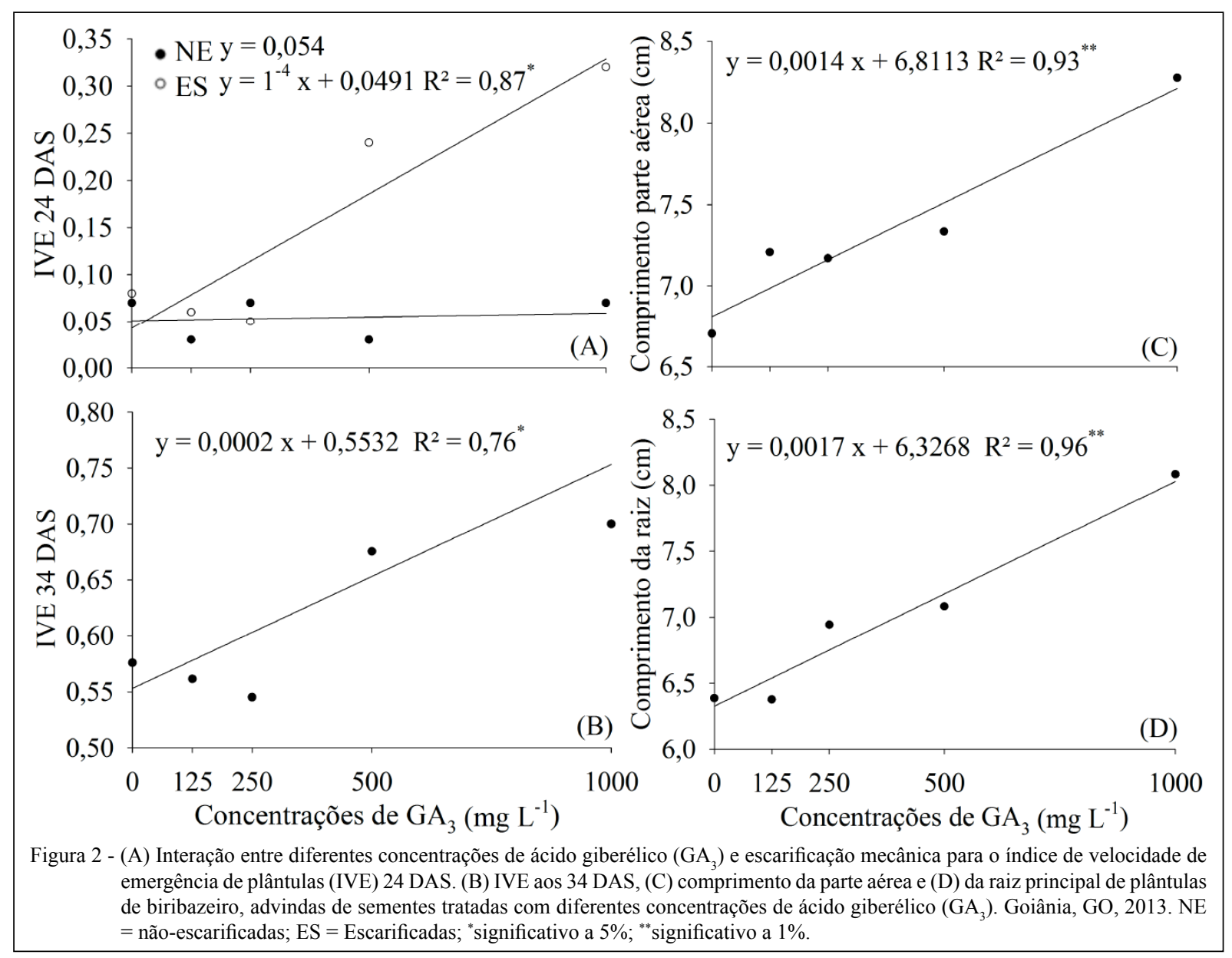

enfraquecimento das estruturas ao redor do embrião (HOOLEY, 1994).

A hipótese alternativa sugere que o regulador de crescimento possa ter sido absorvido pelo revestimento da semente, uma vez que, após a semeadura, o ingrediente ativo difunde, provavelmente, da casca da semente para o meio de crescimento. Então, ele é absorvido pela raiz após a germinação e emergência, ocasionando o maior crescimento da plântula, por aumentarem a elongação e a divisão celular, o que é evidenciado pelo aumento do comprimento da célula e do número de células (TAIZ \& ZEIGER, 2004). Segundo SAUTER \& KENDE (1992), esta resposta com um maior crescimento inicial baseia-se na elongação das células do meristema intercalar, que, ao aumentar de tamanho, promovem a divisão celular. Assim, as maiores taxas de crescimento são observadas pelo aumento na formação de novas células e pela maior elongação celular em resposta à giberelina.

As sementes de biribá devem ser escarificadas, gerando ganho de tempo para formação de mudas, pela emergência mais rápida das plântulas. No entanto, outros experimentos devem ser realizados para confirmar a real necessidade do GA, uma vez que ele pode aumentar o custo de produção, sem ganhos tão significativos para obtenção de mudas de biribá.

\section{CONCLUSÃO}

A escarificação mecânica é eficiente na superação da dormência de sementes de biribá, proporcionando maior emergência inicial e índice de velocidade de emergência de plântulas. O tratamento com ácido giberélico foi positivo porque proporciona aumento na porcentagem e velocidade de emergência, culminando em maior crescimento de raiz e parte aérea.

\section{REFERÊNCIAS}

ALMEIDA, L.F.P. et al. Propagação por enxertia de atemoia 'Thompson' sobre espécies de Rollinia. Revista Brasileira de Fruticultura, v.32, n.2, p.653-656, 2010. Disponível em: 
$<$ http://www.scielo.br/pdf/rbf/v32n2/aop06210.pdf $>$. Acesso em: 28 ago. 2014. doi: 10.1590/S0100-29452010005000058.

ALVES, M.C.S. et al. Superação da dormência em sementes de Bauhinia monandra Britt. e Bauhinia ungulata L. Caesalpinoideae. Revista Brasileira de Sementes, v.22, n.2, p.139-144, 2000. Disponível em: <http://www.abrates. org.br/revista/artigos/ 2000/v22n2/artigo19.pdf $>$. Acesso em: 10 nov. 2013 .

AVELINO, J.I. et al. Métodos de quebra de dormência em sementes de jucá (Caesalpinia ferrea Mart. ex Tul. var. ferrea). Revista Verde de Agroecologia e Desenvolvimento Sustentável, v.7, n.1, p.102-106, 2012. Disponível em: <http://www.gvaa com.br/revista /index.php/RVADS/article/viewFile/853/pdf_374>. Acesso em: 05 maio, 2014.

BRASIL. Ministério da Agricultura, Pecuária e Abastecimento. Regras para análise de sementes. Brasília, DF: Ministério da Agricultura, Pecuária e Abastecimento. Secretaria de Defesa Agropecuária, MAPA/ACS, 2009. 395p.

DUTRA, T.R. et al. Emergência e crescimento inicial da canafístula em diferentes substratos e métodos de superação de dormência. Revista Caatinga, v.25, n.2, p.65-71, 2012. Disponível em: $<$ http://periodicos.ufersa.edu.br/revistas/index.php/sistema/article/ view/2243/ pdf $>$. Acesso em: 12 dez. 2013.

EIRA, M.T.S. et al. Superação da dormência de sementes de Enterolobium contortisiliquum (vell.) morong. - Leguminosae Revista Brasileira de Sementes, v.15, n.2, p.177-181, 1993 Disponível em: <http://www.abrates.org.br/revista/artigos/1993/ v15n2/artigo06.pd $>$. Acesso em: 12 nov. 2013.

FERREIRA, G. et al. Uso de ácido giberélico em sementes de fruta-do-conde (Annona squamosa L.) visando à produção de mudas em diferentes embalagens. Revista Brasileira de Fruticultura, v.24, n.1, p.178-182, 2002. Disponível em: $<$ http://www.scielo.br/scielo.php?script $=$ sci arttext\&pid $=$ S0100$29452002000100039 \& \operatorname{lng}=\mathrm{pt} \& \mathrm{nrm}=\mathrm{iso} \& \mathrm{t} \operatorname{lng}=\mathrm{pt}>$. Acesso em: 10 nov. 2013. doi: 10.1590/S0100-29452002000 100039.

FERREIRA M.G.R.; RIBEIRO, G.D. Coleção de fruteiras tropicais da Embrapa Rondônia. Porto Velho, RO: Embrapa Rondônia, 2006. 14 p. (Comunicado Técnico, 306). Disponível em: <http://www.cpafro.embrapa.br/media/arquivos/publicacoes/ cot306fruteiras. pdf $>$. Acesso em: 20 nov. 2013.

FERREIRA, M.G.R. et al. Superação de dormência em sementes de biribá (Rollinia mucosa (Jacq.) Baill). Revista Brasileira de Sementes, v.31, n.4, p.95-99, 2009. Disponível em: <http://www. scielo.br/pdf/rbs/v31n4/11.pdf>. Acesso em: 21 nov. 2013.

HERNÁNDEZ, L.V. La reproduccion sexual y multiplicacion vegetativa de las anonaceas. Xalapa: Universidade Veracruzana, 1993. $16 \mathrm{p}$

HOOLEY, R. Gibberellins: perception, transduction and responses. Plant Molecular Biology, v.26, n.5, p.1529-1555, 1994. Disponível em: <http://link.springer.com/article/10.1007\%2FBF00016489>. Acesso em: 08 dez. 2014.

LIMA-BRITO, A. et al. Efeito do ácido giberélico (GA $)$ na emergência de plântulas de Annona crassiflora Mart., Annona squamosa L. e Annona muricata L. Magistra, v.18, n.1, p.27-33, 2006.
LORENZI, H. Árvores brasileiras: manual de identificação e cultivo de plantas arbóreas do Brasil. 2.ed. São Paulo: Nova Odessa, 2002. V.2, 384p.

LULA, A.A. et al. Estudos de agentes químicos na quebra de dormência de sementes de Paspalum paniculatum L. Ciência e Agrotecnologia, v.24, n.2, p.358-366, 2000.

MAGUIRE, J.D. Speed of germination aid in selection and evaluation for seedling emergence and vigor. Crop Science, v.2, n.2, p.176-177, 1962. Disponível em: <https://www.crops.org/ publications/cs/abstracts/2/2/CS0020020176>. Acesso em: 21 nov. 2013. doi: 10.2135/cropsci1962.0011183X 000200020033x.

MENEGAZZO, M.L. et al. Efeitos de métodos de superação de dormência em sementes de pinha (Annona squamosa L.). Revista Agrarian, v.5, n.15, p.29-35, 2012. Disponível em: $<$ http://www.periodicos.ufgd.edu.br/index.php/agrarian/article/ view/1285/1010>. Acesso em: 15 nov. 2013.

METIVIER, J.R. Dormência e germinação. In: FERRI, M.G. (Coord.). Fisiologia vegetal. São Paulo: EDUSP, 1979. p.343-392.

NOGUEIRA, E.A. et al. Produção e comercialização de anonáceas em São Paulo e Brasil. Informações Econômicas, v.35, n.2, p.51-54, 2005. Disponível em: <http://www.iea.sp.gov.br/out/ publicacoes/pdf/seto1-0205.pdf>. Acesso em: 21 nov. 2013.

PEREIRA, E.B.C. et al. Quebra da dormência de sementes de araticum. Planaltina, DF: Embrapa Cerrados, 2004. 15p. (Boletim de Pesquisa e desenvolvimento/EMBRAPA Cerrados, 137). Disponível em: <http://www.infoteca.cnptia.embrapa.br/bitstream/ doc/ 569157/1/bolpd 137.pdf $>$. Acesso em: 21 nov. 2013.

ROVERSI, T. et al. Superação de dormência em sementes de acácia negra (Acacia mearnsii Willd.). Revista Brasileira de Agrociência, v.8, n.2, p.161-163, 2002. Disponível em: $<$ http://periodicos.ufpel.edu.br/ojs2/index.php/CAST/article/ view/444/449>. Acesso em: 19 nov. 2013.

SANTOS, C.E. et al. Propagação do biribá (Rollinia mucosa) e sua utilização como porta-enxerto de pinha (Annona squamosa). Acta Scientiarum, v.27, n.3, p.433-436, 2005. Disponível em: $<$ http://periodicos.uem.br/ojs/index.php/ActaSciAgron/article/ view/1404/818>. Acesso em: 21 nov. 2013. doi: 10.4025/ actasciagron.v27i3.1404.

SAUTER, M.; KENDE, H. Gibberellin-induced growth and regulation of the cell division cycle in deepwater rice. Planta, v.188, n.3, p.362-368, 1992. Disponível em: <http://link. springer.com/article/10.1007\%2FBF00192803>. Acesso em: 08 dez. 2014

SILVA, F.A.S.; AZEVEDO, C.A.V. Principal components analysis in the software Assistat-Statistical Attendance. In: WORLD CONGRESS ON COMPUTERS IN AGRICULTURE, 7, 2009, Reno-NV-USA. Proceedings... Reno: American Society of Agricultural and Biological Engineers, p.04-09, 2009. doi: $10.13031 / 2013.29066$.

SOUSA, S.A. et al. Superação da dormência em sementes de pinha. Caatinga, v.21, n.4, p.118-121, 2008. Disponível em: $<$ http://periodicos.ufersa.edu.br/revistas/index.php/sistema/ article/view/24/419>. Acesso em: 29 nov. 2013. 
STENZEL, N.M.C. et al. Superação da dormência em sementes de atemóia e fruta-do-conde. Revista Brasileira de Fruticultura, v.25, n.2, p.305-308, 2003. Disponível em: $<$ http://www.scielo.br/scielo.php?script=sci_arttext\&pid=S0100$29452003000200031 \& \operatorname{lng}=\mathrm{pt \& nrm}=\mathrm{iso} \& \operatorname{tn} \mathrm{ln}=\mathrm{pt}>$. Acesso em: 10 nov. 2013. doi: 10.1590/S0100-29452003000200031.

VIEIRA, R.D.; CARVALHO, N.M. Teste de vigor em sementes. Jaboticabal: FUNEP, 1994. 218p.
TAIZ, L.; ZEIGER, E. Fisiologia vegetal. 3.ed. Porto Alegre: Artmed, 2004. 719p.

WATANABE, H.S. et al. Perfil de comercialização das Anonáceas nas Ceasas brasileiras. Revista Brasileira de Fruticultura, v.36, n.spe1, p.65-70, 2014. Disponível em: <http://www.scielo.br/pdf/rbf/v36nspe1/v36nspe1a07. pdf $>$. Acesso em: 30 ago. 2014. doi: 10.1590/S010029452014000500007. 